\title{
Long-Term Stable Hollowed Silicon for Li-Ion Batteries Based on an Improved Low-Temperature Molten Salt Strategy
}

\author{
Xinxi Li, Binghe Zheng, Long Liu, Guoqing Zhang, Zhongyun Liu, and Wen Luo*
}

Cite This: ACS Omega 2020, 5, 27368-27373

Read Online

ABSTRACT: Nanostructured hollow silicon has attracted tremendous attention as high-performance anode materials in Li-ion battery applications. However, the large-scale production of pure hollowed silicon with long cycling stability is still a great challenge. Here, we report an improved low-temperature molten salt strategy to synthesize nanosized hollowed silicon with a stable structure on a large scale. As an anode material for rechargeable lithium-ion batteries, it exhibits a high capacity, excellent long cycling, and steady rate performance at different current densities. Especially, a high reversible capacity of $2028.6 \mathrm{~mA} \mathrm{~h} \mathrm{~g}^{-1}$ at $0.5 \mathrm{~A} \mathrm{~g}^{-1}$ after 150 cycles, $994.3 \mathrm{~mA} \mathrm{~h} \mathrm{~g}^{-1}$ at $3 \mathrm{~A} \mathrm{~g}^{-1}$ after 500 cycles, and $538.8 \mathrm{mAh} \mathrm{g}^{-1}$ at $5 \mathrm{~A}$ $\mathrm{g}^{-1}$ after 1200 cycles could be obtained. This kind of nanosized hollowed silicon can be applied as a basic anode material in siliconbased composites for long-term stable Li-ion battery applications.

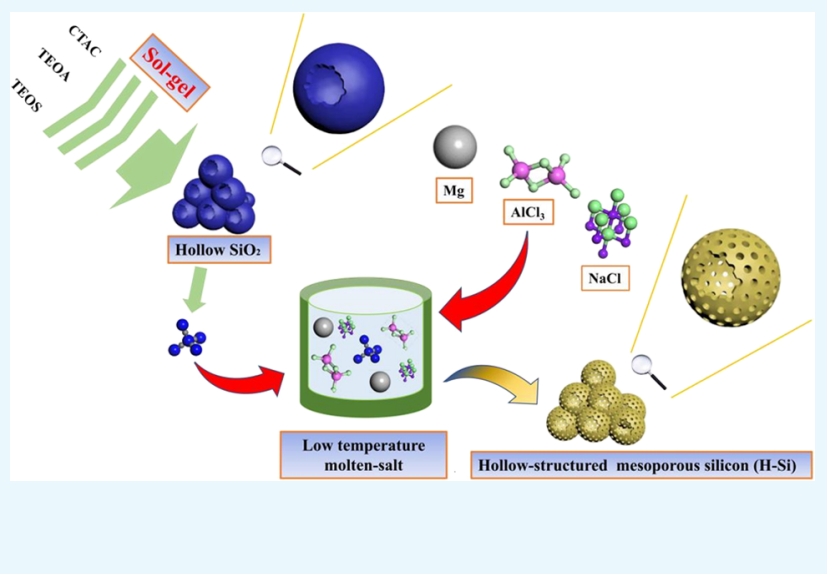

\section{INTRODUCTION}

Hollow-nanostructured silicon-based materials have been considered as a promising option in high-performance energy storage and conversion applications, especially for highcapacity Li-ion batteries (LIBs). ${ }^{1-4}$ After years of development, fundamental studies focus on self-templated methods (such as the Kirkendall effect and ion exchange method) and optimized magnesiothermic/aluminothermic reduction at a quite high temperature to form hollow nanostructures by introducing a thin stable interface. ${ }^{5-8}$ However, the above strategies are rarely applied to obtain long-term stable hollow silicon with a high yield. Therefore, it is still a great challenge to develop an effective method for the large-scale preparation of hollow-structured and long-term stable silicon nanomaterials at a lower temperature.

In recent years, the metals magnesium $(\mathrm{Mg})$ and aluminum (Al) have been utilized to reduce various silicon reactants into silicon nanocrystalline at a lower temperature range by the molten salt method. ${ }^{9}$ However, the above strategy fails to obtain long-term stable hollow silicon due to the absence of a stable interface in the reaction. Liu et al. reported the magnesiothermic reduction in molten $\mathrm{LiCl} / \mathrm{KCl}$ salts at 550 ${ }^{\circ} \mathrm{C}$. However, this method obtains a low yield (only 10\%). ${ }^{10}$

More recently, Gao et al. has proposed a simple strategy to successfully synthesize hollow silicon in molten salts at $300{ }^{\circ} \mathrm{C}$ by tuning the interdiffusion rates of reactants via an initially coated carbon layer. ${ }^{11}$ This hollow-structured silicon exhibited excellent rate performance and cycling stability as an anode material in LIBs. Qian et al. developed a low-temperature (200 ${ }^{\circ} \mathrm{C}$ ) molten method to synthesize hollow silicon from microsized high-silicon zeolite with a higher yield (about $40 \%)^{8}$ using $\mathrm{Al}$ (or $\mathrm{Mg}$ ) $/ \mathrm{AlCl}_{3}$ salts. As anode materials for LIBs, this kind of hollow silicon displays outstanding long-term cycling stability with high reversible capacity. However, the low yield limits further applications of hollow silicon.

Herein, we develop a facile and improved low-temperature molten salt strategy to prepare long-term stable and nanostructured hollow silicon $(\mathrm{H}-\mathrm{Si})$. Although the high-quality $\mathrm{H}-\mathrm{Si}$ is difficult to be directly obtained from pure silicon nanoparticles on a large scale, it is easier to control the reduced process of stable hollow-structured silica spheres $\left(\mathrm{H}-\mathrm{SiO}_{2}\right)$. Therefore, we propose that large-scale and high-quality $\mathrm{H}-\mathrm{Si}$ are prepared via $\mathrm{Mg}$-thermal reduction of $\mathrm{H}-\mathrm{SiO}_{2}$ in molten $\mathrm{NaCl} / \mathrm{AlCl}_{3}$ at $200{ }^{\circ} \mathrm{C}$ (Scheme 1) in which $\mathrm{H}-\mathrm{SiO}_{2}$ is prepared through the principle of chemical homology with some modifications (see the Experimental Methods section). ${ }^{12,13}$ As an anode for rechargeable lithium-ion batteries, the synthesized hollow silicon exhibits a high reversible capacity of $2028.6 \mathrm{mAh} \mathrm{g}^{-1}$ at $0.5 \mathrm{~A} \mathrm{~g}^{-1}$ after 150 cycles, $994.3 \mathrm{mAh} \mathrm{g}^{-1}$ at $3 \mathrm{~A} \mathrm{~g}^{-1}$ after 500 cycles, and $538.8 \mathrm{mAh} \mathrm{g}^{-1}$ at $5 \mathrm{~A} \mathrm{~g}^{-1}$ after 1200 cycles. Meanwhile, the initial Coulombic efficiency is as high as $91.6 \%$ at $0.1 \mathrm{~A} \mathrm{~g}^{-1}$. This reported

Received: August 1, 2020

Accepted: September 28, 2020

Published: October 12, 2020 
Scheme 1. Formation of $\mathrm{H}-\mathrm{Si}$ through Reduction of $\mathrm{H}-\mathrm{SiO}_{2}$ with $\mathrm{Mg}$ Powder in Molten Salts at a Low Temperature

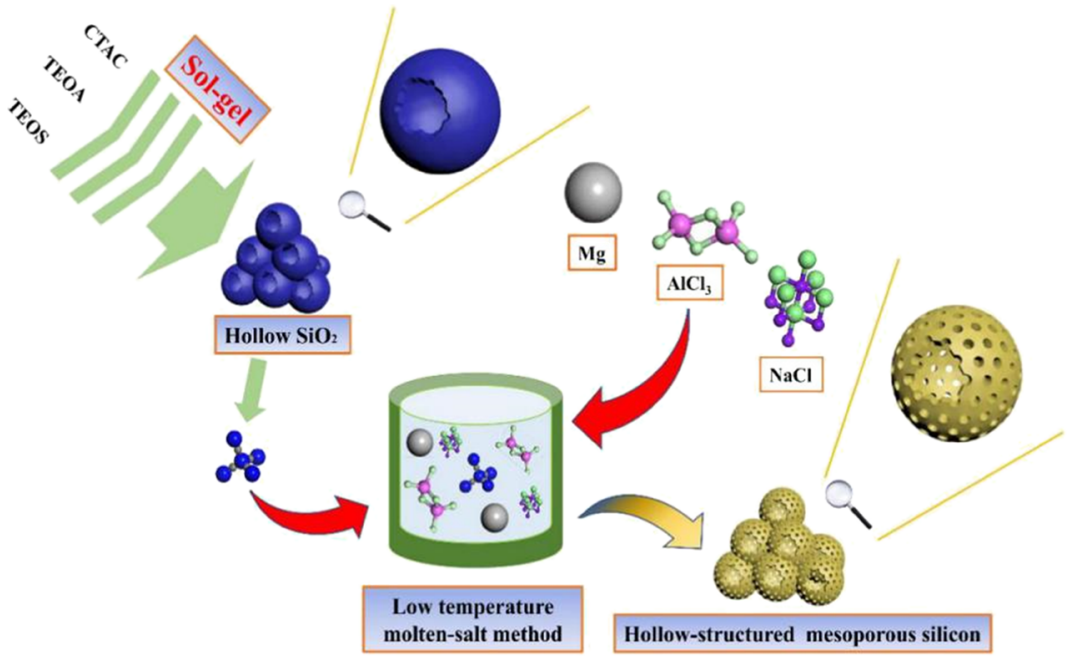

a

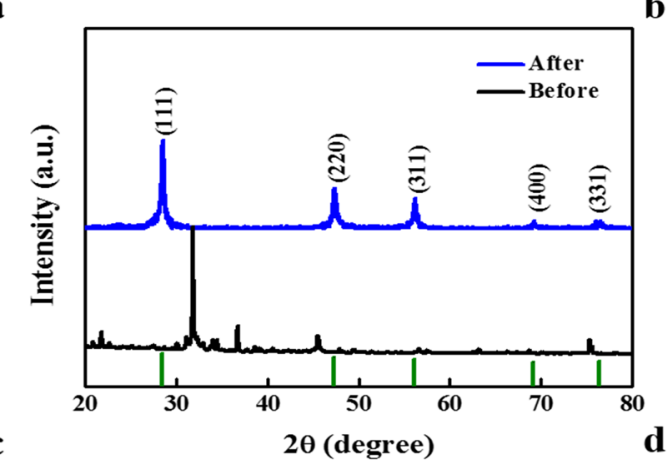

b
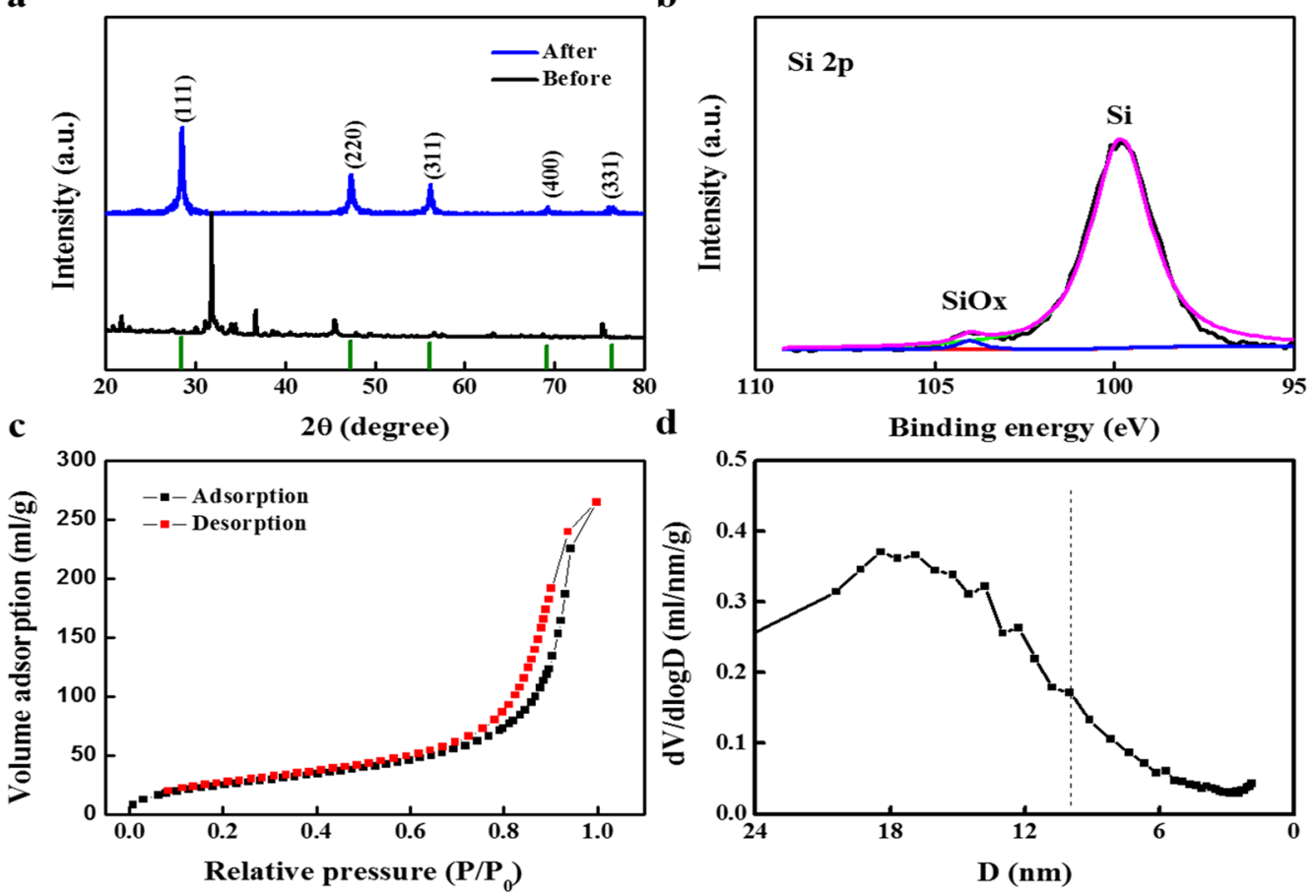

Figure 1. (a) XRD of the reduction product of $\mathrm{H}-\mathrm{SiO}_{2}$ before and after being washed with acid. (b) High-resolution XPS spectrum of $\mathrm{Si} 2 \mathrm{p}$. (c) $\mathrm{N}_{2}$ adsorption/desorption curves. (d) Pore size distribution curve of $\mathrm{H}-\mathrm{Si}$.

strategy can obtain large-scale and high-quality $\mathrm{H}-\mathrm{Si}$ as the basic anode material in silicon-based composites for long-term stable LIB applications.

\section{RESULTS AND DISCUSSION}

2.1. Morphology and Structure. Figure la exhibits the $\mathrm{X}$-ray diffraction (XRD) patterns of the sample after washing with dilute $\mathrm{HCl}$ and $\mathrm{HF}$, indicating that the by-products are easily removed. The five different diffraction peaks position of $28,47,56,69$, and $76^{\circ}$ corresponded to (111), (220), (311), (400), and (331) crystal planes of silicon (JPCDS\#75-0590). The X-ray photoelectron spectroscopy (XPS) spectrum is applied to confirm the surface contents of the as-prepared $\mathrm{H}-$ $\mathrm{Si}$ (Figure S1). As shown in Figure $1 \mathrm{~b}$, the Si $2 \mathrm{p}$ spectrum of $\mathrm{H}-\mathrm{Si}$ can be deconvolved into two contributions. One dominant peak at $99.6 \mathrm{eV}$ corresponds to the bonding of $\mathrm{Si}-\mathrm{Si}$. The other relatively weak peak located at $103.5 \mathrm{eV}$ is attributed to a very small amount of $\mathrm{SiO}_{x}{ }^{12}$ Meanwhile, the ratio of $\mathrm{Si}-\mathrm{O}$ and $\mathrm{Si}-\mathrm{Si}$ is calculated to be about $2 \%$ by XPS data, which is quite small compared to those of other $\mathrm{H}-\mathrm{Si}$ materials. Moreover, the specific surface area of $\mathrm{H}-\mathrm{Si}$ is about $95.4 \mathrm{~m}^{2} \mathrm{~g}^{-1}$ based on the $\mathrm{N}_{2}$ adsorption/desorption data (Figure 1c). The increased specific surface area is mainly due to the existence of a mesoporous structure in the prepared $\mathrm{H}-$ $\mathrm{Si}$ via the low-temperature molten salt method. It can be proved by the average pore diameter (about $11 \mathrm{~nm}$ ) according to the pore size distribution data (Figure 1d). The increased specific surface area and mesoporous structure are very important for improving the long-term cycling stability of LIBs at a relatively high current density. 
To further observe the microtopography and mesoporous structure, scanning electron microscopy (SEM) and transmission electron microscopy (TEM) are utilized. As can be observed from the SEM images (Figure 2a,c), both $\mathrm{H}-\mathrm{SiO}_{2}$
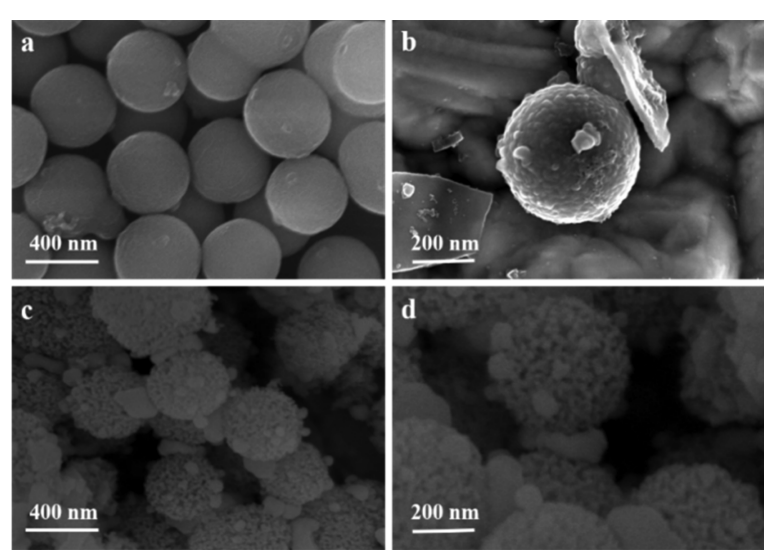

Figure 2. SEM images of $(\mathrm{a}, \mathrm{b}) \mathrm{H}-\mathrm{SiO}_{2}$ and (c, d) $\mathrm{H}-\mathrm{Si}$.

and $\mathrm{H}-\mathrm{Si}$ are independent and uniform nanoparticles. Compared to $\mathrm{H}-\mathrm{SiO}_{2}$ (Figure $2 \mathrm{~b}$ ), the formed mesoporous structure can be observed in $\mathrm{H}-\mathrm{Si}$ (Figure 2d) after the reduction reaction, which can be also proved by the above BET result. Furthermore, the TEM image of $\mathrm{H}-\mathrm{Si}$ (Figure 3a)
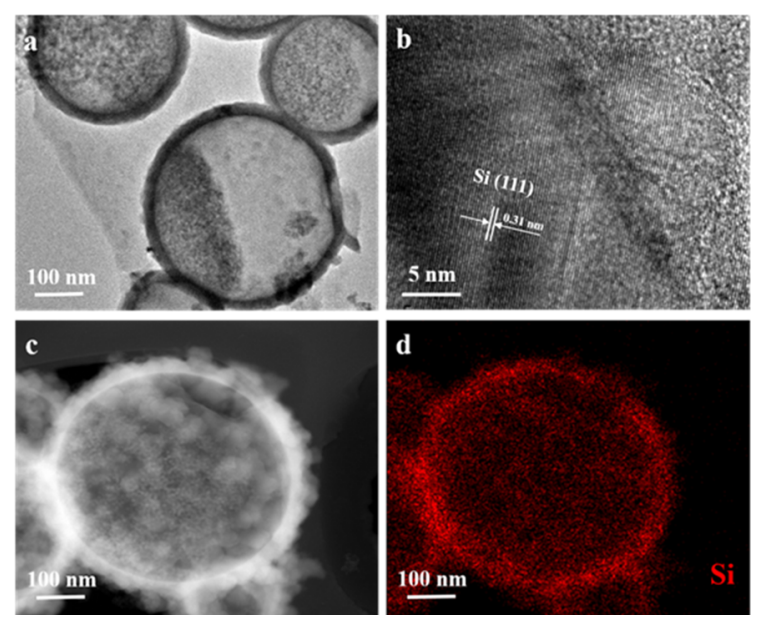

Figure 3. TEM images of $\mathrm{H}-\mathrm{Si}$ : (a) low resolution and (b) high resolution. EDS mapping images of (c) $\mathrm{H}-\mathrm{Si}$ and (d) Si element.

exhibits the relatively well-dispersed hollow-structured nanoparticles, which are much better than previously reported Si nanoparticles. This is because of the good hollow structure of the original $\mathrm{H}-\mathrm{SiO}_{2}$ with a larger particle size and very small amount of $\mathrm{SiO}_{x .}{ }^{13}$ From the TEM image of $\mathrm{H}-\mathrm{Si}$ nanoparticles (Figure 3a), an average diameter of $300-400 \mathrm{~nm}$ can be observed, which is consistent with the above SEM images. The HRTEM image (Figure 3b) reveals lattice fringes of the obtained $\mathrm{H}-\mathrm{Si}$. Also, the interplanar distance (about $0.31 \mathrm{~nm}$ ) can be found corresponding to the (111) silicon fcc phase while the crystal lattice can also be observed in fast Fourier transform (FTT) patterns (Figure S2) ${ }^{14}$ Moreover, as can be observed from energy-dispersive spectrometry (EDS) results (Figure $3 \mathrm{c}, \mathrm{d}$ ), the $\mathrm{Si}$ element in the $\mathrm{H}-\mathrm{Si}$ shows a partial uniform distribution at the edge of nanoparticles because the central part is mainly a hollow structure with a mesoporous construction.

The relatively uniform large particle size and neat hollow structure with a mesoporous construction are beneficial to the long-term stability of this H-Si for LIB applications. ${ }^{11}$

2.2. Electrochemical Performance. To evaluate the electrochemical properties of the prepared $\mathrm{H}-\mathrm{Si}$ anodes for rechargeable LIBs, a series of electrochemical tests are carried out. Figure $4 a$ shows the first three discharge-charge cycle performance of $\mathrm{H}-\mathrm{Si}$, exhibiting high discharge and charge capacities, i.e., 3150 and $2885 \mathrm{mAh} \mathrm{g}^{-1}$, respectively, corresponding to the initial Coulombic efficiency of $91.6 \%$ at $0.1 \mathrm{~A} \mathrm{~g}^{-1}$ current. As we know, the capacity loss in the first cycle can be attributed to the formation of the solid electrolyte interphase (SEI) and amorphous $\mathrm{Li}_{x} \mathrm{Si}^{15}$ It should be mentioned that the second and the third curves overlapped well, indicating a fine reversible reaction between the lithium ion and the $\mathrm{H}-\mathrm{Si}$ electrode. The relative Coulombic efficiency benefits from contributions of the hollow-structured mesoporous construction, which is significantly much higher than that of the commercial nanosilicon material (Figure S3a) and is comparable to those of the recently reported Si-based electrodes. $^{16,17}$ Figure $4 \mathrm{~b}$ exhibits the first five cyclic voltammetry $(\mathrm{CV})$ curves of the $\mathrm{H}-\mathrm{Si}$ electrode with typical lithiation/delithiation peaks. It is noted that one peak around $1.21 \mathrm{~V}$ is due to the formation of an SEI layer that disappears in the following cycles, indicating that the SEI layer is stable. To further study the cycling performance, galvanostatic discharge-charge tests are used. From Figure 4c, the $\mathrm{H}-\mathrm{Si}$ electrode exhibits a capacity of $2028.6 \mathrm{mAh} \mathrm{g}^{-1}$ at a current density of $0.5 \mathrm{~A} \mathrm{~g} \mathrm{~g}^{-1}$ after 150 cycles while the commercial nanosilicon electrode only retains a capacity of $700 \mathrm{mAh} \mathrm{g}^{-1}$ even though the initial discharge capacity is as high as 3500 $\mathrm{mAh} \mathrm{g}^{-1}$ (Figure S3b).

Moreover, the $\mathrm{H}-\mathrm{Si}$ electrode exhibits excellent long-term cycling stability with a high specific capacity of $994.3 \mathrm{mAh} \mathrm{g}^{-1}$ at $3 \mathrm{~A} \mathrm{~g}^{-1}$ after 500 cycles (Figure $4 \mathrm{~d}$ ) and $538.8 \mathrm{mAh} \mathrm{g}^{-1}$ at 5 $\mathrm{A} \mathrm{g}^{-1}$ after 1200 cycles (Figure S4 and Table S2), which is more than 2 -fold that of by previous low-temperature aluminothermic reduction. ${ }^{4}$ The outstanding long cycling performance is better than most of pure hollowed silicon and even comparable to the best silicon-based composite electrodes $^{8,11,13}$ in recent papers, which benefits from the regular and stable hollowed mesoporous structure. Furthermore, the $\mathrm{H}-\mathrm{Si}$ electrode also shows a good rate capability (Figure S5 and Table S3), as estimated by increasing current densities of $0.1,0.5,1,3$, and $5 \mathrm{~A} \mathrm{~g}^{-1}$. As the density returns to $0.1 \mathrm{~A} \mathrm{~g}^{-1}$, a reversible capacity of $2534.4 \mathrm{mAh} \mathrm{g}^{-1}$ with a capacity retention ratio of $92 \%$ could be obtained. The above great electrochemical performance is resulting from the increased specific surface area and enhanced reversible reaction between the lithium ion and the $\mathrm{H}-\mathrm{Si}$ electrode owing to the uniform and steady structure. ${ }^{11,18,19}$ This kind of $\mathrm{H}-\mathrm{Si}$ holds great promise as a basic anode material in silicon-based composites for future long-term LIB applications.

2.3. Long-Term Stability of Hollowed Structure. To further demonstrate the long-term stability of $\mathrm{H}-\mathrm{Si}$, the microscopic morphology and volume change of $\mathrm{H}-\mathrm{Si}$ electrodes before and after different cycles at $3 \mathrm{~A} \mathrm{~g}^{-1}$ are characterized by SEM (Figure 5). It is well known that the microstructure of traditional silicon would be severely damaged and pulverized after long cycles. ${ }^{16}$ Obviously, the $\mathrm{H}-\mathrm{Si}$ electrode shows a relatively complete surface structure 
a

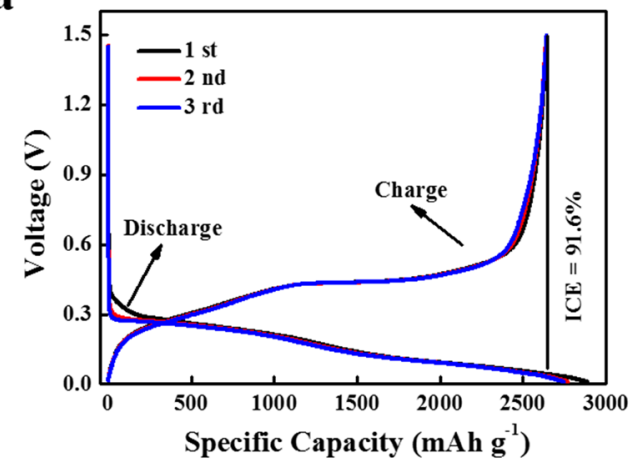

c

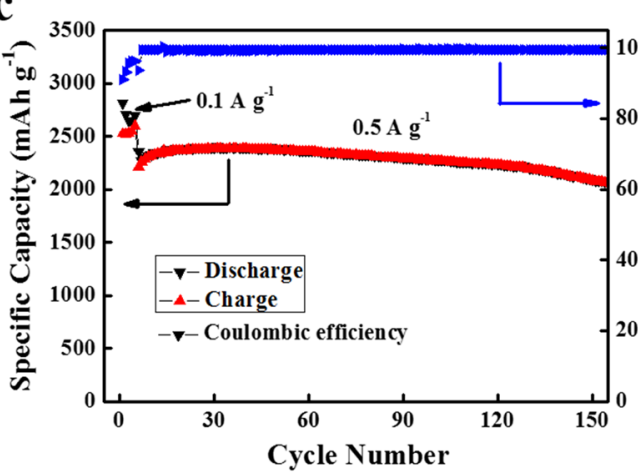

b

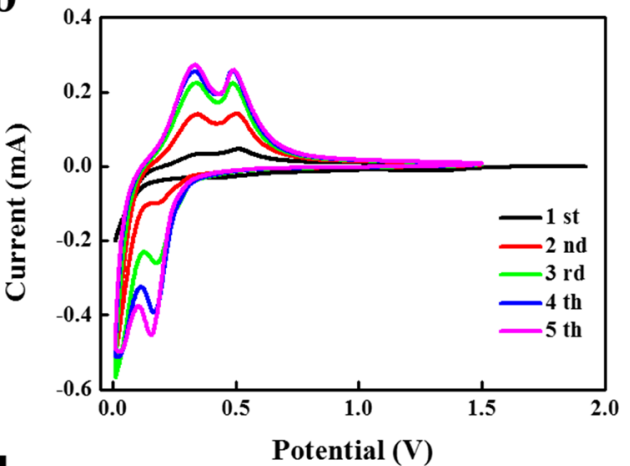

d

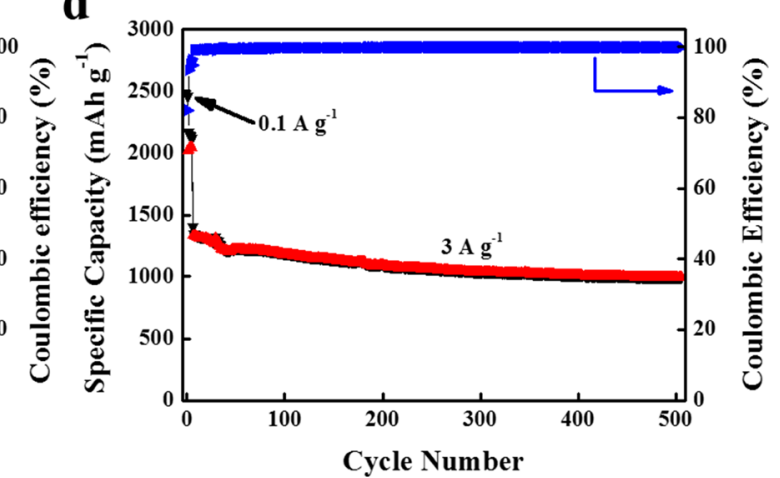

Figure 4. (a) First three discharge-charge curves at $0.1 \mathrm{~A} \mathrm{~g}^{-1}$ current. (b) First five CV curves. Cycling performance (c) at $0.5 \mathrm{~A} \mathrm{~g}^{-1}$ current after 150 cycles and (d) at $3 \mathrm{~A} \mathrm{~g}^{-1}$ current after 500 cycles of the $\mathrm{H}-\mathrm{Si}$ electrode.

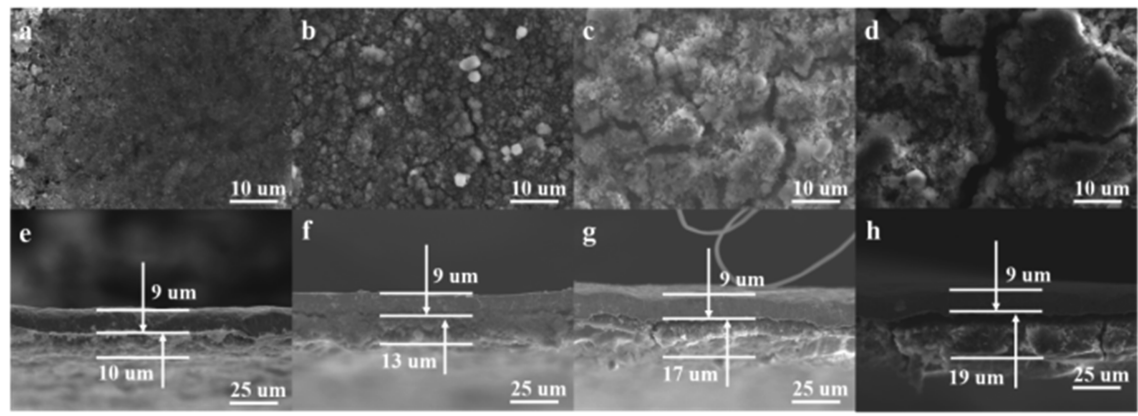

Figure 5. Microscopic morphology and volume expansion of $\mathrm{H}-\mathrm{Si}$ electrodes after different cycles at $3 \mathrm{~A} \mathrm{~g}^{-1}$ : (a, e) 0th, (b, f) 100th, (c, g) 300th, and $(\mathrm{d}, \mathrm{h})$ 500th cycle.

and a very small volume expansion after 500 cycles at $3 \mathrm{~A} \mathrm{~g}^{-1}$ compared to the initial $\mathrm{H}-\mathrm{Si}$ before cycles. This is due to the stable hollow structure and increased specific surface area, which can effectively buffer the volume expansion during the cycling process. The above result indicates the enhanced structural stability and excellent long-term cycling performance that are comparable to those of the recent Si-based composite electrodes. ${ }^{8,11,14}$ Moreover, the electrochemical impedance spectroscopy (EIS) test (Figure S6) of $\mathrm{H}-\mathrm{Si}$ also exhibits a slight increase in ohmic resistance and electron transfer impedance after 500 cycles at $3 \mathrm{~A} \mathrm{~g} \mathrm{~g}^{-1}$ compared to the original state. This is quite important for the increase in electrochemical performance and limit of volume expansion. Moreover, a similar result can also be obtained in the longterm cycling at a much higher current of $5 \mathrm{~A} \mathrm{~g}^{-1}$. This is consistent with the above SEM result, further indicating the enhanced structural stability, which is very important for the long-cycling-life LIB applications at a quite high current density.

\section{CONCLUSIONS}

In summary, the long-term stable nanocrystalline $\mathrm{H}-\mathrm{Si}$ with a high field of $80 \%$ can be obtained using metal $\mathrm{Mg}$ powder in molten $\mathrm{NaCl} / \mathrm{AlCl}_{3}$ reagent at $200{ }^{\circ} \mathrm{C}$ from as-prepared $\mathrm{H}-$ $\mathrm{SiO}_{2}$. This method not only achieves the large-scale synthesis but also effectively forms a stable and mesoporous structure with increased specific surface area and enhanced reversible reaction between the lithium ion and $\mathrm{H}-\mathrm{Si}$ electrode. As an anode material for rechargeable lithium-ion batteries, the $\mathrm{H}-\mathrm{Si}$ material exhibits high capacity, excellent long cycling, and steady rate performance. Especially, the $\mathrm{H}-\mathrm{Si}$ shows a high reversible capacity of $2028.6 \mathrm{mAh} \mathrm{g}^{-1}$ at $0.5 \mathrm{~A} \mathrm{~g}^{-1}$ after 150 cycles, $994.3 \mathrm{mAh} \mathrm{g}^{-1}$ at $3 \mathrm{~A} \mathrm{~g}^{-1}$ after 500 cycles, and 538.8 $\mathrm{mAh} \mathrm{g}^{-1}$ at $5 \mathrm{~A} \mathrm{~g}^{-1}$ after 1200 cycles. Meanwhile, the initial Coulombic efficiency is as high as $91.6 \%$ at $0.1 \mathrm{~A} \mathrm{~g}^{-1}$. This reported facile strategy opens a valuable way for long-term stable $\mathrm{H}-\mathrm{Si}$, which can be utilized as a basic anode material for long-cycling-life LIB applications. 


\section{EXPERIMENTAL METHODS}

4.1. Synthesis of Hollow-Structured Silica Spheres $\left(\mathrm{H}-\mathrm{SiO}_{2}\right)$. All the reagents were of analytical grade and used without further purification. $\mathrm{Mg}$ powder, $\mathrm{NaCl}, \mathrm{AlCl}_{3}$, and commercial $\mathrm{Si}$ powder were purchased from Sinopharm Chemical Reagent Co., Ltd. In a typical preparation of $\mathrm{H}-$ $\mathrm{SiO}_{2}, 1.5 \mathrm{~g}$ of cetyltrimethylammonium chloride (CTAC, 97\%, Aladdin) and $0.5 \mathrm{~g}$ of triethanolamine (TEOA, 99\%, Aladdin) were fully dissolved in $35 \mathrm{~mL}$ of deionized water under magnetic stirring for $1 \mathrm{~h}$ to obtain a uniform solution. The solution was transferred to an oil bath at $80{ }^{\circ} \mathrm{C}$ while $5 \mathrm{~mL}$ of tetraethyl orthosilicate (TEOS, 99\%, Aladdin) was slowly dropped into the above solution under magnetic stirring. After that, the reaction was carried out for $6 \mathrm{~h}$ at $80{ }^{\circ} \mathrm{C}$. The final $\mathrm{H}-\mathrm{SiO}_{2}$ was attained after washing with distilled water several times and drying in a vacuum overnight at $60{ }^{\circ} \mathrm{C} . .^{20,21}$

4.2. Synthesis of Hollow-Structured Nanocrystalline Silicon $(\mathrm{H}-\mathrm{Si})$. Compared to the traditional low-temperature molten salt method, ${ }^{8,11,22}$ we have made some obvious improvements to obtain high-quality $\mathrm{H}-\mathrm{Si}$ on a large scale, including using $\mathrm{H}-\mathrm{SiO}_{2}$ as the silicon source, lowering the heating rate, and prolonging the reaction time. In a typical synthesis of $\mathrm{H}-\mathrm{Si}, 1 \mathrm{~g}$ of $\mathrm{H}-\mathrm{SiO}_{2}$ was mixed with $1 \mathrm{~g}$ of $\mathrm{Mg}$ powder, $5 \mathrm{~g}$ of $\mathrm{AlCl}_{3}$, and $8 \mathrm{~g}$ of $\mathrm{NaCl}$ thoroughly. The mixture was loaded in a $50 \mathrm{~mL}$ stainless steel autoclave and sealed in an argon-filled glovebox with the moisture and oxygen level below $0.1 \mathrm{ppm}$. Thereafter, the glovebox was transferred to a box-type muffle furnace and heated to $200{ }^{\circ} \mathrm{C}$ with a rising rate of $2{ }^{\circ} \mathrm{C}$ $\min ^{-1}$. The reaction was kept at this temperature for $12 \mathrm{~h}$. The obtained powder was stirred in $1 \mathrm{~mol} \mathrm{~L}^{-1} \mathrm{HCl}$ solution for $6 \mathrm{~h}$ to remove $\mathrm{Mg}$-bearing and excessive salt after furnace cooling to room temperature. Then, the raw product was transferred to a $5 \mathrm{wt} \% \mathrm{HF}$ solution for etching for $15 \mathrm{~min}$ to remove the residual $\mathrm{SiO}_{2}$ after washing by centrifugation. The final $\mathrm{H}-\mathrm{Si}$ particles were obtained by washing and filtrating several times with ethanol and then vacuum drying at $60{ }^{\circ} \mathrm{C}$ overnight. ${ }^{8,11,22}$ According to the typical experiment, the final yield of the product is over $80 \%$, which is much higher than that of the existing molten salt system at the same temperature (only about $40 \%){ }^{8}$ It is noted that a similar yield still can be maintained even in a 15 -fold enlarged experiment (Table S1). Compared to existing low-temperature molten salt method in ref 4 , the higher yield of $\mathrm{H}-\mathrm{Si}$ obtained from the reduction of $\mathrm{H}-\mathrm{SiO}_{2}$ is due to the more efficient reaction process based on the combined effects of the original silicon source $\left(\mathrm{H}-\mathrm{SiO}_{2}\right)$, lower heating rate, longer reaction time, and addition of $\mathrm{NaCl}$ salt. The stable high yield of this improved low-temperature molten salt method can be utilized in large-scale preparation. Furthermore, this method can effectively avoid the abundant existence of $\mathrm{SiO}_{x}$ and provide a mesoporous structure simultaneously. The related reaction using $\mathrm{Mg}$ powder in molten $\mathrm{NaCl} / \mathrm{AlCl}_{3}$ may run as follows: ${ }^{1,22}$

$$
\begin{aligned}
2 & -\mathrm{Mg}+\mathrm{SiO}_{2}+7-\mathrm{AlCl}_{3}+\mathrm{NaCl} \\
& \rightarrow \mathrm{Si}+2-\mathrm{MgAl}_{2} \mathrm{Cl}_{8}+2-\mathrm{AlOCl}+\mathrm{NaAlCl}_{4}
\end{aligned}
$$

4.3. Material Characterizations. X-ray diffraction (XRD) patterns were recorded on a D/Max-Ultima IV powder X-ray diffractometer using $\mathrm{Cu} \mathrm{K} \alpha$ radiation in the $2 \theta$ range from 20 to $80^{\circ}$. Scanning electron microscopy (SEM) was conducted on an S-3400 microscope from Japan. Transmission electron microscopy (TEM) experiments were conducted on an FEI
Tecnai G2 F20 microscope (Japan) operated at $200 \mathrm{kV}$ with an EDS analyzer. The thermogravimetric analysis (TGA) was carried out using SDT 2960 from American TA Instruments. The X-ray photoelectron spectroscopy (XPS) analysis was carried out on a Thermo Scientific ESCALAB 250Xi system. The Brunauer-Emmett-Teller (BET, 3H-2000PS1, BeiShiDe Instrument) method was utilized to calculate the specific surface area $(\mathrm{SBET})$ using the adsorption data at $P / P_{0}=0.04-$ 0.32 .

4.4. Material Characterizations. The prepared $\mathrm{H}-\mathrm{Si}$ was mixed with carbon black and binder (polyacrylic acid) with a mass ratio of 70:15:15 for several hours. Then, the slurry was coated on the copper foil and vacuum-dried at $60{ }^{\circ} \mathrm{C}$ for $12 \mathrm{~h}$. Finally, the electrodes were cut into a disk shape and a CR2032 cell was assembled in an argon-filled glovebox with lithium metal as the counter and the reference electrodes and microporous polypropylene (Celgard 2400) as the separator. The electrolyte of half cells was $1 \mathrm{M} \mathrm{LiPF}_{6}$ in a mixture of ethylene carbonate/dimethyl carbonate with a volume ratio of $1: 1$. Half coin cells were assembled in an Ar-filled glovebox with the moisture and oxygen level below $0.1 \mathrm{ppm}$ and then rested for $24 \mathrm{~h}$. The galvanostatic charge-discharge tests were measured on a battery testing system (Neware, BTS7.5, China) at room temperature $\left(25{ }^{\circ} \mathrm{C} \pm 1\right)$ under a voltage range of $0.01-1.5 \mathrm{~V}$ versus $\mathrm{Li} / \mathrm{Li}^{+}$. Cyclic voltammetry (CV) measurements were carried out on electrochemical workstation (CHI670D, CH Instruments) at a scanning rate of $0.1 \mathrm{mV} \mathrm{s}^{-1}$ in a voltage range of $0.01-1.5 \mathrm{~V}$. The EIS measurements were also conducted by the electrochemical workstation CHI670D with an amplitude of $5 \mathrm{mV}$ at a frequency range from $0.01 \mathrm{~Hz}$ to $100 \mathrm{kHz}$.

\section{ASSOCIATED CONTENT}

\section{Supporting Information}

The Supporting Information is available free of charge at https://pubs.acs.org/doi/10.1021/acsomega.0c03693.

XPS pattern and FTT pattern of $\mathrm{H}-\mathrm{Si}$, cycling performance, specific capacity and Coulombic efficiency of the $\mathrm{H}-\mathrm{Si}$ electrode at $5 \mathrm{~A} \mathrm{~g}^{-1}$ current density, rate performance and specific capacity of the $\mathrm{H}-\mathrm{Si}$ electrode at different currents, first three discharge-charge cycle and cycling performance at $0.5 \mathrm{~A} \mathrm{~g}^{-1}$ current density of the commercial nanosilicon electrode, EIS curves of the $\mathrm{H}-\mathrm{Si}$ electrode before and after 100 and 500 cycles at 3 $\mathrm{A} \mathrm{g}^{-1}$, and three enlarged experiments of $\mathrm{H}-\mathrm{Si}$ with yields (PDF)

\section{AUTHOR INFORMATION}

\section{Corresponding Author}

Wen Luo - School of Materials and Energy, Guangdong University of Technology, Guangzhou 510006, P.R. China; 이이.org/0000-0003-0605-7350; Email: wenluo@ gdut.edu.cn

\section{Authors}

Xinxi Li - School of Materials and Energy, Guangdong University of Technology, Guangzhou 510006, P.R. China

Binghe Zheng - School of Materials and Energy, Guangdong University of Technology, Guangzhou 510006, P.R. China

Long Liu - School of Materials and Energy, Guangdong University of Technology, Guangzhou 510006, P.R. China 
Guoqing Zhang - School of Materials and Energy, Guangdong University of Technology, Guangzhou 510006, P.R. China

Zhongyun Liu - School of Chemical and Biomolecular Engineering, Georgia Institute of Technology, Atlanta, Georgia

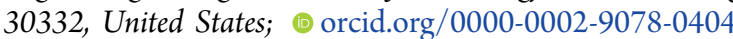

Complete contact information is available at:

https://pubs.acs.org/10.1021/acsomega.0c03693

\section{Author Contributions}

X.L. and W.L. conceived the experiments and led the project. B.Z. and L.L. performed material synthesis and characterization. X.L., G.Z., and Z. L. contributed to scientific discussion and provided experimental guidance. X.L., L.L., and W.L. contributed to the interpretation of the data and commented on the manuscript. L.L. and W.L. wrote the paper with input and discussion from all authors.

\section{Notes}

The authors declare no competing financial interest.

\section{ACKNOWLEDGMENTS}

This work was supported by the National Natural Science Foundation of China (grant nos. 21875046 and 51803036).

\section{REFERENCES}

(1) Huang, X.; Yang, J.; Mao, S.; Chang, J.; Hallac, P. B.; Fell, C. R.; Metz, B.; Jiang, J.; Hurley, P. T.; Chen, J. Controllable Synthesis of Hollow Si Anode for Long-Cycle-Life Lithium-Ion Batteries. Adv. Mater. 2014, 26, 4326-4332.

(2) Liu, N.; Wu, H.; McDowell, M. T.; Yao, Y.; Wang, C.; Cui, Y. A Yolk-Shell Design for Stabilized and Scalable Li-ion Battery Alloy Anodes. Nano Lett. 2012, 12, 3315-3321.

(3) Lin, H.; Weng, W.; Ren, J.; Qiu, L.; Zhang, Z.; Chen, P.; Chen, X.; Deng, J.; Wang, Y.; Peng, H. Twisted Aligned Carbon Nanotube/ Silicon Composite Fiber Anode for Flexible Wire-Shaped Lithium-Ion Battery. Adv. Mater. 2014, 26, 1217-1222.

(4) Zhou, Z.; Pan, L.; Liu, Y.; Zhu, X.; Xie, X. From sand to fast and stable silicon anode: Synthesis of hollow Si@void@C yolk-shell microspheres by aluminothermic reduction for lithium storage. Chin. Chem. Lett. 2019, 30, 610-617.

(5) Yin, Y.; Rioux, R. M.; Erdonmez, C. K.; Hughes, S.; Somorjai, G. A.; Alivisatos, A. P. Formation of Hollow Nanocrystals through the Nanoscale Kirkendall Effect. Science 2004, 304, 711-714.

(6) Xing, A.; Zhang, J.; Bao, Z.; Mei, Y.; Gordin, A. S.; Sandhage, K. H. A Magnesiothermic Reaction Process for the Scalable Production of Mesoporous Silicon for Rechargeable Lithium Batteries. Chem. Commun. 2013, 49, 6743-6745.

(7) Wang, L.; Gao, B.; Peng, C.; Peng, X.; Fu, J.; Chu, P. K.; Huo, K. Bamboo Leaf Derived Ultrafine Si Nanoparticles and Si/C Nanocomposites for High-Performance Li-ion Battery Anodes. Nanoscale 2015, 7, 13840-13847.

(8) Lin, N.; Han, Y.; Zhou, J.; Zhang, K.; Xu, T.; Zhu, Y.; Qian, Y. A Low Temperature Molten Salt Process for Aluminothermic Reduction of Silicon Oxides to Crystalline Si for Li-ion Batteries. Energy Environ. Sci. 2015, 8, 3187-3191.

(9) Mishra, K.; Zheng, J.; Patel, R.; Estevez, L.; Jia, H.; Luo, L.; ElKhoury, P. Z.; Li, X.; Zhou, X.-D.; Zhang, J.-G. High Performance Porous Si@C Anodes Synthesized by Low Temperature Aluminothermic Reaction. Electrochim. Acta 2018, 269, 509-516.

(10) Liu, X.; Giordano, C.; Antonietti, M. A Molten-Salt Route for Synthesis of Si and Ge Nanoparticles: Chemical Reduction of Oxides by Electrons Solvated in Salt Melt. J. Mater. Chem. 2012, 22, 54545459.

(11) Gao, P.; Huang, X.; Zhao, Y.; Hu, X.; Cen, D.; Gao, G.; Bao, Z.; Mei, Y.; Di, Z.; Wu, G. Formation of Si Hollow Structures as Promising Anode Materials through Reduction of Silica in $\mathrm{AlCl}_{3}-\mathrm{NaCl}$ Molten Salt. ACS Nano 2018, 12, 11481-11490.
(12) Diéguez, L.; Caballero, D.; Calderer, J.; Moreno, M.; Martínez, E.; Samitier, J. Optical Gratings Coated with Thin $\mathrm{Si}_{3} \mathrm{~N}_{4}$ Layer for Efficient Immunosensing by Optical Waveguide Lightmode Spectroscopy. Biosensors 2012, 2, 114-126.

(13) Han, Y.; Lin, N.; Qian, Y.; Zhou, J.; Tian, J.; Zhu, Y.; Qian, Y. A Scalable Synthesis of N-doped Si Nanoparticles for High-Performance Li-ion Batteries. Chem. Commun. 2016, 52, 3813-3816.

(14) Luo, W.; Wang, X.; Meyers, C.; Wannenmacher, N.; Sirisaksoontorn, W.; Lerner, M. M.; Ji, X. Efficient Fabrication of Nanoporous $\mathrm{Si}$ and $\mathrm{Si} / \mathrm{Ge}$ Enabled by a Heat Scavenger in Magnesiothermic Reactions. Sci. Rep. 2013, 3, 2222.

(15) Chen, Y.; Li, Y.; Wang, Y.; Fu, K.; Danner, V. A.; Dai, J.; Lacey, S. D.; Yao, Y.; Hu, L. Rapid, in Situ Synthesis of High Capacity Battery Anodes through High Temperature Radiation-Based Thermal Shock. Nano Lett. 2016, 16, 5553-5558.

(16) Liu, L.; Li, X.; Zhang, G.; Zhang, Z.; Fang, C.; Ma, H.; Luo, W.; Liu, Z. Enhanced Stability Lithium-Ion Battery Based on Optimized Graphene/Si Nanocomposites by Templated Assembly. ACS Omega 2019, 4, 18195-18202.

(17) Zhang, K.; Xia, Y.; Yang, Z.; Fu, R.; Shen, C.; Liu, Z. StructurePreserved 3D Porous Silicon/Reduced Graphene Oxide Materials as Anodes for Li-ion Batteries. RSC Adv. 2017, 7, 24305-24311.

(18) Sun, W.; Hu, R.; Liu, H.; Zeng, M.; Yang, L.; Wang, H.; Zhu, M. Embedding Nano-Silicon in Graphene Nanosheets by Plasma Assisted Milling for High Capacity Anode Materials in Lithium-ion Batteries. J. Power Sources 2014, 268, 610-618.

(19) Sun, W.; Hu, R.; Zhang, H.; Wang, Y.; Yang, L.; Liu, J.; Zhu, M. A Long-Life Nano-Silicon Anode for Lithium-ion Batteries: Supporting of Graphene Nanosheets Exfoliated from Expanded Graphite by Plasma-Assisted Milling. Electrochim. Acta 2016, 187, $1-10$.

(20) Teng, Z.; Su, X.; Zheng, Y.; Sun, J.; Chen, G.; Tian, C.; Wang, J.; Li, H.; Zhao, Y.; Lu, G. Mesoporous Silica Hollow Spheres with Ordered Radial Mesochannels by a Spontaneous Self-Transformation Approach. Chem. Mater. 2013, 25, 98-105.

(21) Fan, W.; Lu, N.; Shen, Z.; Tang, W.; Shen, B.; Cui, Z.; Shan, L.; Yang, Z.; Wang, Z.; Jacobson, O.; Zhou, Z.; Liu, Y.; Hu, P.; Yang, W.; Song, J.; Zhang, Y.; Zhang, L.; Khashab, N. M.; Aronova, M. A.; Lu, G.; Chen, X. Generic Synthesis of Small-Sized Hollow Mesoporous Organosilica Nanoparticles for Oxygen-independent X-ray-activated Synergistic Therapy. Nat. Commun. 2019, 10, 1241.

(22) Lin, N.; Han, Y.; Wang, L.; Zhou, J.; Zhou, J.; Zhu, Y.; Qian, Y. Preparation of Nanocrystalline Silicon from $\mathrm{SiCl}_{4}$ at $200{ }^{\circ} \mathrm{C}$ in Molten Salt for High-Performance Anodes for Lithium-ion Batteries. Am. Ethnol. 2015, 127, 3893-3896. 